\title{
Mielorradiculopatia esquistossomótica
}

\author{
Schistosomal myeloradiculopathy
}

\section{Luciana Cristina dos Santos Silva ${ }^{1}$, Pedro Ernane Maciel $^{2}$, João Gabriel Ramos Ribas ${ }^{3}$, Sílvio Roberto de Sousa Pereira ${ }^{4}$, José Carlos Serufo ${ }^{1}$, Luciene Mota Andrade ${ }^{5}$, Carlos Maurício Antunes ${ }^{1}$ e José Roberto Lambertucci ${ }^{1}$}

\begin{abstract}
RESUM0
A mielorradiculopatia esquistossomótica é a forma ectópica mais grave e incapacitante da infecção pelo Schistosoma mansoni. A sua prevalência em área endêmica tem sido subestimada. 0 diagnóstico baseia-se na presença de sintomas neurológicos decorrentes de lesões da medula espinhal em nível torácico baixo e/ou lombar alto, na demonstração da infecção esquistossomótica por técnicas microscópicas ou sorológicas e na exclusão de outras causas de mielite transversa. 0 tratamento precoce, com esquistossomicidas e corticoesteróides, mostra-se eficaz na maioria dos casos e os pacientes não tratados não se recuperam ou morrem. Não há consenso sobre doses e duração do tratamento, mas estudo recente sugere que os corticoesteróides devam ser usados por pelo menos seis meses. Como o diagnóstico é presuntivo e 0 tratamento essencialmente clínico, há que se manter alerta para a presença da doença, aperfeiçoar a propedêutica e, dessa forma, evitar-se a laminectomia rotineira. Com o advento da ressonância magnética da medula espinhal houve grande avanço no diagnóstico da esquistossomose medular. Como conseqüência, o número de casos de mielopatia esquistossomótica relatados tem aumentado rapidamente.
\end{abstract}

Palavras-chaves: Esquistossomose. Mielopatia. Neuroesquistossomose. Mielorradiculopatia. Medula espinhal.

\begin{abstract}
Schistosomal myeloradiculopathy is the most severe and disabling ectopic form of schistosomiasis mansoni. Its prevalence in endemic areas has been underestimated. The diagnosis relies on the presence of low thoracic/upper lumbar neurological symptoms, demonstration of the Schistosoma mansoni infection by microscopic or serologic techniques, and exclusion of other causes of transverse myelitis. When treatment with antischistosomal drugs and corticosteroids is started early, the clinical response is surprisingly good and those left untreated do not improve and frequently die. There is no consensus about doses and duration of treatment, but a recent study suggests that when steroids are given for at least 6 months clinical improvement is enhanced. As the diagnosis of SMR is presumptive and treatment is essentially clinical, physicians should be aware of the disease and more research is needed to increase the accuracy of the diagnostic methods and, hence, to avoid routine laminectomy. With the advent of magnetic resonance imaging of the spinal cord the diagnosis of this ectopic form of the disease was facilitated. In accordance, the number of cases of schistosomal myelopathy reported is increasing rapidly.
\end{abstract}

Key-words: Schistosomiasis. Myelopathy. Neuroschistosomiasis. Myeloradiculopathy. Spinal cord.

Três espécies de platelmintos trematódeos são os causadores da maioria dos casos de esquistossomose humana: 0 Schistosoma haematobium, descrito por Bilharz em 1852, o Schistosoma japonicum, reconhecido e nomeado por Katsurada em 1904, e o Schistosoma mansoni, separado do S. haematobium por Sambon em $1907^{4} 335253$.

0 sistema nervoso central ( $\mathrm{SNC}$ ) pode ser acometido, não só nas infecções pelo Schistosoma mansoni, mas também

\footnotetext{
1. Serviço de Doenças Infecciosas e Parasitárias da Faculdade de Medicina da Universidade Federal de Minas Gerais, Belo Horizonte, MG. 2. IRM/IMRAD, Belo Horizonte, MG. 3. Hospital Sarah Kubitscheck, Belo Horizonte, MG. 4. Divisão de Neurologia do Hospital das Clínicas da Universidade Federal de Minas Gerais, Belo Horizonte, MG. 5. Serviço de Radiologia do Laboratório Hermes Pardini.

Endereço para correspondência: Dr. José Roberto Lambertucci. FM/UFMG. Av Alfredo Balena 190, Santa Efigênia, 30130-100, Belo Horizonte, MG, Brasil.

e-mail: lamber@uai.com.br

Recebido para publicação em 19/1/2004

Aceito em 4/5/2004
} 
pelo S. haematobium e 0 S. japonicum ${ }^{20}{ }^{51}$. A deposição assintomática de ovos no SNC é freqüente ${ }^{63}$. Nas formas sintomáticas, as duas primeiras espécies citadas apresentam-se mais freqüentemente com síndrome mielorradicular, e a última, com envolvimento cerebral. A prevalência da esquistossomose cerebral sintomática entre indivíduos infectados pelo Schistosoma japonicum é de 2 a $4 \%{ }^{41113}$. A mielorradiculopatia esquistossomótica (MRE), forma mais comum da doença esquistossomótica do sistema nervoso, relaciona-se mais freqüentemente à esquistossomose mansoni.

0 primeiro registro de esquistossomose ectópica foi feito por Yamagiwa em 1889, quinze anos antes de 0 agente etiológico, 0 S. japonicum, ser descrito ${ }^{116}$. 0 paciente tinha história de episódios recorrentes de epilepsia e 0 exame post-mortem de seu cérebro revelou a presença de granulomas. Nesses granulomas havia grande número de estruturas que foram identificadas, oportunamente, como ovos de S. japonicum. Em 1905, Shimamura e Tsunoda relataram a presença de granulomas no hemisfério cerebral esquerdo de um indivíduo com história de epilepsia e hemiplegia à direita. Esses investigadores também observaram lesões esquistossomóticas no segmento lombar da medula espinhal de um segundo paciente com história de mielite transversa.

Ferguson, em 1913, descreveu a presença de ovos de Schistosoma no SNC de um egípcio que morreu com paraplegia e esquistossomose vesical ${ }^{34}$. A primeira descrição de lesões ectópicas do S. haematobium foi feita por Day e Kenawy, em 1911, que encontraram ovos do parasita em granulomas medulares $^{28}$. Em 1930, identificou-se 0 S. mansoni como 0 causador de mielopatia esquistossomótica em um paciente que residira no Brasil ${ }^{33}$.

Em 1948, Faust publicou revisão sobre esquistossomose ectópica $^{33}$. De 82 casos descritos, anotou-se acometimento cerebral em 56 pacientes e, em oito havia evidência de lesão medular; três estavam infectados pelo S. mansoni. Já naquela época, 0 autor enfatizou a importância de atrair a atenção médica para a doença e o necessário esforço diagnóstico, uma vez que 0 número de casos era suficientemente grande e as complicações resultantes freqüentemente graves: "Nos relatos de casos, tem sido costumeiro a maioria dos escritores se referir à esquistossomose ectópica como rara ou muito rara. Essas designações não são mais aplicáveis, apesar de essas síndromes serem relativamente infreqüentes".

Os trabalhos de revisão da literatura publicados após o relato de Faust vêm reforçar a importância das manifestações ectópicas da esquistossomose, com ênfase no acometimento do SNC. Scrimgeour e Gajdusek, em 1985, encontraram relato de deposição de ovos no cérebro em 17 pacientes infectados pelo S. mansoni e em quatro infectados pelo $\mathrm{S}$. haematobium ${ }^{98}$. Cinqüenta e dois relatos de casos de mielopatia por S. mansoni e 12 por S. haematobium foram reportados pelos autores. Em outra revisão da literatura, publicada em 1999, a autora recuperou 231 casos de MRE descritos entre 1930 e $1996^{35}$. Em 181, a doença foi atribuída ao S. mansoni, em 29 ao S. haematobium e, em um caso ${ }^{47}$, os ovos de ambas as espécies foram identificados no tecido medular.

\section{EPIDEMIOLOGIA}

A prevalência da mielorradiculopatia esquistossomótica em área endêmica não é conhecida ${ }^{107290} 107$. Como o número de casos relatados vem aumentando rapidamente, admite-se a ocorrência de falha na notificação de casos novos e que a morbidade desta forma ectópica tem sido subestimada9 3543547794 .

Em 1981, por exemplo, Scrimgeour ${ }^{97}$ chamou a atenção dos pesquisadores para a importância da esquistossomose como causa de paraplegia em áreas endêmicas. Segundo esse autor, em estudos realizados no norte da Tanzânia, a esquistossomose era responsável por $1 \%$ dos casos de paraplegia não traumática e era a causa presumida em outros $5 \%$. Spina-França e colaboradores ${ }^{105}$ encontraram 5,6\% de casos de MRE entre 353 pacientes com mielopatias não-traumáticas e não-tumorais internados no Hospital de Clínicas da Faculdade de Medicina da Universidade de São Paulo. Desta forma, é possível que um número significativo de casos de mielopatia de etiologia indefinida em áreas endêmicas de esquistossomose esteja relacionado a esta doença' 5101926414777106 .

Os homens são mais acometidos pela MRE (71 a 83\% dos casos descritos), o que pode ser explicado, em parte, por sua maior exposição ocupacional. A idade das pessoas acometidas pela MRE varia entre 1 e 68 anos, com média de 26 anos $^{35} 7194$

\section{PATOGENIA}

A patogenia da mielopatia esquistossomótica permanece desconhecida, porém, admite-se que a resposta inflamatória do hospedeiro aos ovos presentes no tecido nervoso constitua 0 principal determinante das lesões do SNC ${ }^{59} 7980{ }^{106}$. A resposta inflamatória pode variar de reação intensa do hospedeiro resultando em granulomas ou massas expansivas, até reação mínima sem expressão clínica. Vermes adultos, às vezes, são vistos nos vasos subaracnóides da medula espinhal; as lesões medulares granulomatosas se dão, entretanto, em torno dos ovos depositados ${ }^{61} 8284$.

Em torno do local de deposição do ovo observa-se área de células do tecido nervoso em processo de necrose lítica e de coagulação. Externamente a esta zona há um envelope de macrófagos, células epitelióides e células gigantes, circundados por infiltrado inflamatório rico em eosinófilos e linfócitos. À medida que a lesão progride a infiltração por fibroblastos pode resultar em encapsulamento do ovo por fibrose. Em alguns casos necropsiados encontram-se ovos no tecido medular sem qualquer reação inflamatória23 .

A contribuição de processo auto-imune disparado pela infecção esquistossomótica, provocando vasculite e isquemia cerebral, também deve ser admitida, mas faltam dados que confirmem esta hipótese.

A deposição de ovos do S. mansoni no cérebro e meninges mostra-se mais freqüente nos pacientes com esquistossomose hepatoesplênica. A migração para o cérebro 
se faz através dos shunts arteriovenosos pulmonares ou portopulmonares e ocorre sem manifestações clínicas. Em 1981, Pittella e Lana-Peixoto encontraram ovos de S. mansoni em $26 \%$ dos 46 cérebros de hepatoesplênicos necropsiados ${ }^{82}$. Na verdade, a deposição assintomática de ovos do S. mansoni, tanto no encéfalo como na medula espinhal, revelou-se mais comum do que a forma sintomática da doença ${ }^{79}{ }^{80}$. A mielorradiculopatia, ao contrário, ocorre com maior frequêencia nas formas aguda e intestinal crônica' 26707887.

Os ovos e vermes podem deslocar-se através do fluxo venoso retrógrado pelo plexo venoso vertebral epidural de Batson ${ }^{12}$, avalvular, que conecta o sistema venoso portal e a veia cava às veias do canal espinhal ( Figura 1). Dessa forma, os ovos atingem 0 SNC através da oviposição local ou por embolização ${ }^{2324} 6479$. A maior incidência de mielopatia na região lombosacra explicase, provavelmente, por esse mecanismo de migração.

Além disso, estudos de necropsias mostraram que os ovos de S. haematobium são mais freqüentemente depositados no cérebro do que os ovos de S. mansoni ${ }^{3}$. Os ovos desta última

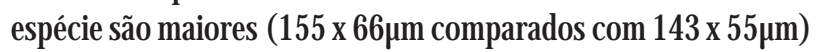
e foi sugerido que a espícula lateral do ovo do S. mansoni pode também impedir sua progressão pelos vasos sangǘneos ${ }^{21}{ }^{58}$. Essas são hipóteses aventadas para justificar a tendência ao alojamento dos ovos de S. mansoni nas regiões mais baixas do plexo venoso vertebral.

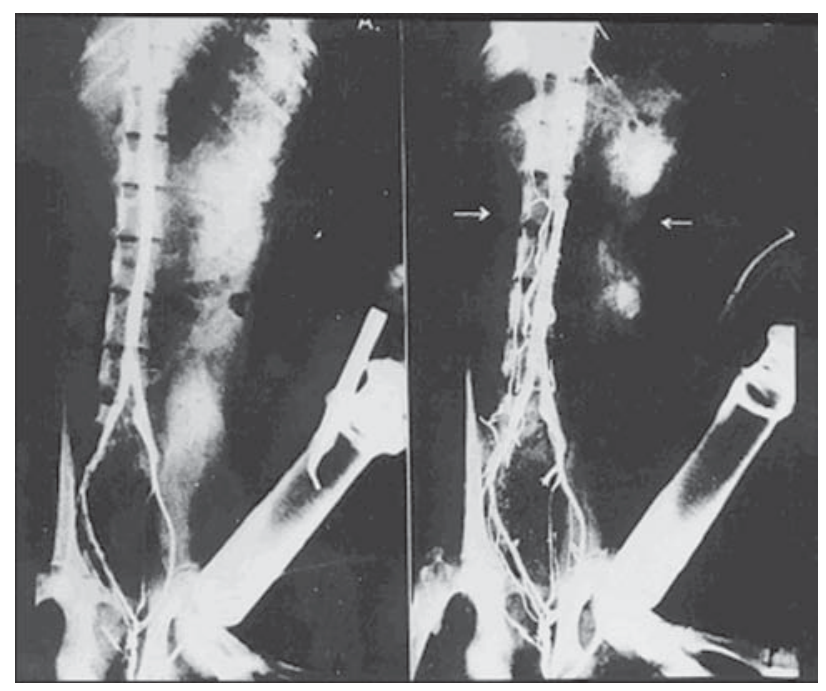

Figura 1 - Radiografia simples durante a injeção de contraste iodado na veia dorsal do pênis de macaco Rhesus. 0 contraste progride para cima através da veia cava inferior. Ȧdireita, após compressão abdominal com uma toalha, o contraste passa para as veias vertebrais (Batson, 1940) ${ }^{12}$. Experimento clássico que mostra como metástases ou vermes/ovos podem migrar para a medula espinhal.

\section{FORMAS CLÍNICAS}

Adeposição dos ovos no SNC provoca reação inflamatória variável de acordo com 0 hospedeiro, produzindo quatro formas principais de lesão, baseadas nos aspectos anatômicos e manifestações clínicas, dentre elas, perda de força, dores radiculares, déficit sensitivo, distúrbio esfincteriano e alterações dos reflexos'11 1417252632586488102106109 .

Granulomatosa. Granulomas se formam em regiões circunscritas do SNC, devido à reação inflamatória em torno do ovo, produzindo lesão expansiva tumoral, com efeito de massa e destruição do tecido circunjacente. Acomete geralmente o cone medular e é descrita na mielografia ou mielotomografia computadorizada como um defeito de enchimento associado ou não ao bloqueio do canal medular.

Mielítica. Năo há lesão expansiva macroscópica medular; a reação inflamatória tecidual é microscópica com necrose, vacuolização e atrofia do tecido nervoso e menos freqüentemente induz a formação de granulomas. Clinicamente, observam-se sinais e sintomas de mielite transversa rapidamente progressiva, sem alterações à mielografia ou mielotomografia computadorizada. A evolução clínica desta forma de MRE mostra-se desfavorável.

Radicular. Granulomas são formados na superfície das raízes nervosas, principalmente na cauda eqüina. Observa-se clinicamente uma síndrome multirradicular associada a alterações sensoriais e motoras de distribuição assimétrica. Pode-se encontrar espessamento de raízes nervosas na mielografia ou mielotomografia computadorizada. Freqüentemente, se associa a outra forma da doença medular.

Vascular. Vasculite de origem imunológica nos ramos da artéria espinhal anterior produzindo infartos medulares secundários 5785101102 .

A MRE granulomatosa é a forma mais freqüentemente diagnosticada através da mielografia e mielotomografia. Com 0 uso mais recente da ressonância magnética ( $\mathrm{RM}$ ) para estudo da medula, mais casos da forma mielítica têm sido revelados, 0 que sugere que esta forma da doença tem sido subdiagnosticada pelos outros métodos de imagem ${ }^{48}$. A sobreposição destas formas clínicas é usual na doença medular esquistossomótica ${ }^{37} 3955$. A forma clínica mais comum é a mielorradicular.

Santos e colaboradores identificaram 31 (55,3\%) casos correspondentes à forma mielorradicular entre 56 pacientes estudados, seguido pela forma mielítica, com 15 (28,6\%) casos $^{94}$. Peregrino e colaboradores já haviam encontrado distribuição similar de formas clínicas em 21 pacientes estudados (mielorradiculite em $66,7 \%$ dos casos e mielítica em 33,3\%) ${ }^{77}$.

\section{DIAGNÓSTIC0}

De acordo com o Centro para Controle e Prevenção de Doenças de Atlanta ${ }^{46}$, 0 diagnóstico da MRE baseia-se em: 1) evidência clínica de lesão neurológica torácica baixa ou lombar alta; 2) demonstração de exposição à esquistossomose por técnicas microscópicas ou sorológicas; 3) exclusão de outras causas de mielite transversa.

Desta forma, os critérios utilizados conseguem estabelecer um diagnóstico provável. A dificuldade de execução de exames complementares em nosso meio para a exclusão de outras causas de mielite transversa dificulta ainda mais a definição diagnóstica da MRE. A demonstração de ovos 
no tecido nervoso através de biópsia ou necropsia representa a única prova incontestável do acometimento medular pelo Schistosoma. Entretanto, o estudo histológico da medula espinhal envolve a realização de procedimento invasivo e com riscos de seqüelas, para diagnóstico de uma doença cujo tratamento é eminentemente clínico e favorável.

Tendo isto em vista e a estimativa de incidência de MRE em áreas endêmicas ${ }^{77} 105$, torna-se de extrema importância 0 esforço para o estabelecimento do diagnóstico não-cirúrgico.

O diagnóstico diferencial da MREinclui: trauma medular, injeção intratecal, radiação, tumores, deficiência de vitamina B12 ou excesso de folato, síndrome antifosfolípide, vasculite diabética ou autoimune, mielite por HIV, HTLV ou HSV, síflis, abscessos medulares, tuberculose e mielopatia associada ao vírus B da hepatite, siringomielia, neurocisticercose 252744454886105 (Tabela 1).

Apesar de o diagnóstico presuntivo ser feito sem necessidade de se recorrer à laminectomia medular, ela continua sendo importante nos casos em que há dúvida diagnóstica ou sinais de bloqueio medular. Há casos descritos de paciente com exame parasitológico de fezes e biópsia retal negativos para ovos de S. mansoni, com diagnóstico confirmado pela biópsia medular ${ }^{103}$.

\section{MANIFESTAÇÕES CLÍNICAS}

A MRE pode se manifestar sem história clínica prévia ou diagnóstico de doença esquistossomótica, ou mesmo muitos anos após o desaparecimento de manifestações intestinais da infecção pelo parasita. Eventualmente, pode associar-se a outra forma ectópica da esquistossomose ${ }^{95}$.

A manifestação clínica inicial mais freqüente da MRE é a dor lombar ou de membros inferiores ( 51 a $77 \%$ dos casos) ${ }^{35} 36{ }^{94}$. Seguem-se, a disfunção vesical (12\%), fraqueza de membros inferiores (7\%), parestesia (6\%) e impotência sexual ( 0,7\%). Estas manifestações neurológicas surgem de forma aguda ou subaguda, com piora progressiva e acumulativa de sinais e sintomas, instalando-se 0 quadro clínico neurológico completo geralmente em 15 dias. Ocasionalmente, essa evolução pode ser lenta e ocorrer ao longo de meses e anos ${ }^{43} 474955637677$.

Em alguns casos a dor lombar ou em membros inferiores regride ou desaparece à medida que os outros sinais e sintomas vão surgindo ou se tornando mais evidentes ${ }^{11} 89112$. Observa-se, ocasionalmente, melhora clínica espontânea. Quando ocorre, entretanto, há recorrência das manifestações neurológicas 436457112114 .

Alguns autores sugerem que 0 aumento da pressão intra-abdominal por esforço físico ou trauma possa desencadear a MRE24 254773109 .

Na Tabela 2, alinham-se as manifestações clínicas observadas após a evolução completa do quadro neurológico. 0 nível da lesão, definido pelo exame neurológico, localiza-se, com freqüência, nas regiões torácica baixa ou lombar da medula

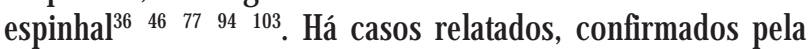
histologia, de lesões esquistossomóticas isoladas da medula

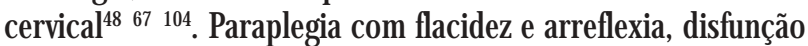
esfincteriana e sensitiva dominam o quadro clínico, quando 0

Tabela 1 - Diagnóstico diferencial da mielorradiculopatia esquistossomótica e exames complementares.

\begin{tabular}{ll}
\hline Diagnóstico diferencial & Exames complementares \\
\hline Trauma medular & Radiografia, tomografia, ressonância magnética \\
Injeção intratecal de contraste ou quimioterapia & História clínica \\
Radiação & História clínica, diagnóstico de neoplasia \\
Tumores & História clínica, tomografia, ressonância magnética, \\
& cintilografia óssea, ultra-som de abdômen \\
Mielopatia por deficiência de B12 & Dosagem de Vitamina B12 sérica \\
Mielopatia por excesso de folato & História clínica, dosagem de folato sérico \\
Síndrome antifosfolípide & Dosagem de anticorpos antifosfolípide \\
Vasculite diabética & História clínica, glicemia, hemoglobina glicosilada \\
Vasculite auto-imune & História clínica, FAN, p-ANCA, c-ANCA \\
Mielite pelo HIV & Anti-HIV no soro \\
Mielite pelo HTLV-1 & Anti-HTLV-1 no soro \\
Mielite pelo herpes vírus & Anti-herpes no soro (IgG, IgM) \\
Síflis & VDRL, FTA-abs \\
Abscessos medulares & Radiografia, tomografia, ressonância magnética \\
Tuberculose & História clínica, pesquisa de baar no líquor, \\
& PCR no líquor, PPD, radiografia de tórax e \\
Hepatites B e C & coluna vertebral e ressonância magnética \\
Esclerose múltipla & HBsAg, anti-HBs, anti-HBc total, anti-HCV \\
Neurocisticercose & Ressonância magnética do cérebro e medula \\
Siringomielia & Ressonância magnética do cérebro e medula \\
\hline FAN= fator antinuclear; p-ANCA= anticorpo anticitoplasma de neutróilo & Ressonância magnética da medula \\
de neutróillo intracitoplasmático; Perinuclear; c-ANCA= anticorpo anticitoplasma & \\
\end{tabular}


Tabela 2 - Principais manifestações da mielorradiculopatia esquistossomótica em sete estudos clínicos.

\begin{tabular}{|c|c|c|c|c|c|c|c|c|c|c|c|c|c|c|}
\hline \multirow[t]{2}{*}{ Sinais e sintomas } & \multicolumn{2}{|c|}{$\begin{array}{l}\text { Peregrino } \\
(1988)\end{array}$} & \multicolumn{2}{|c|}{$\begin{array}{l}\text { Haribhai } \\
\text { (1991) }\end{array}$} & \multicolumn{2}{|c|}{$\begin{array}{l}\text { Ferrari } \\
\text { (1995) }\end{array}$} & \multicolumn{2}{|c|}{$\begin{array}{l}\text { Andrade Filho } \\
\text { (2001) }\end{array}$} & \multicolumn{2}{|c|}{$\begin{array}{l}\text { Santos } \\
\text { (1996) }\end{array}$} & \multicolumn{2}{|c|}{$\begin{array}{l}\text { Nobre } \\
\text { (2001) }\end{array}$} & \multicolumn{2}{|c|}{$\begin{array}{c}\text { Silva } \\
(2002)\end{array}$} \\
\hline & $\mathrm{n}^{0}$ & $\%$ & $\mathrm{n}^{0}$ & $\%$ & $\mathrm{n}^{0}$ & $\%$ & $\mathrm{n}^{0}$ & $\%$ & $\mathrm{n}^{0}$ & $\%$ & $\mathrm{n}^{0}$ & $\%$ & $\mathrm{n}^{0}$ & $\%$ \\
\hline Dor lombar ou em MMI & 21 & 100,0 & 11 & 79,0 & 53 & 98,0 & 16 & 100,0 & 43 & 76,8 & 20 & 87,0 & 15 & 93,8 \\
\hline Fraqueza em MMII & 5 & 23,8 & 14 & 100,0 & 54 & 100,0 & 16 & 100,0 & 48 & 85,7 & 20 & 87,0 & 16 & 100,0 \\
\hline capaz de andar & & & 4 & 28,6 & 20 & 37,0 & & & & & & & 4 & 25,0 \\
\hline incapaz de andar & & & 10 & 71,4 & 34 & 63,0 & & & & & 16 & 70,0 & 12 & 75,0 \\
\hline Anestesia/hipoestesia & 21 & 100,0 & 14 & 100,0 & 48 & 89,0 & 16 & 100,0 & & & & & 16 & 100,0 \\
\hline cervical & & & 1 & 7,1 & & & & & & & & & & \\
\hline torácica & 9 & 42,9 & 4 & 28,6 & 18 & 37,0 & 9 & 56,0 & & & & & & \\
\hline torácica alta & 1 & 4,7 & 1 & 7,1 & & & & & & & & & & \\
\hline torácica baixa & 8 & 38,1 & 3 & 21,4 & & & & & & & & & 11 & 68,7 \\
\hline Cone/cauda & 12 & 57,1 & 9 & 64,3 & & & & & & & & & & \\
\hline lombar & & & 7 & 50,0 & 18 & 37,0 & 7 & 44,0 & & & & & 5 & 31,3 \\
\hline sacral & & & 2 & 14,3 & 7 & 15,0 & & & & & & & & \\
\hline radicular & & & & & 5 & 10,0 & & & & & & & & \\
\hline Parestesia de MMII & 20 & 95,2 & & & 51 & 94,0 & 16 & 100,0 & 41 & 73,2 & 22 & 95,6 & 13 & 81,3 \\
\hline Disfunção vesical & 20 & 95,2 & 12 & 86,0 & 53 & 98,0 & 16 & 100,0 & 49 & 87,5 & 23 & 100,0 & 16 & 100,0 \\
\hline Disfunção intestinal & & & & & 45 & 83,0 & 15 & 94,0 & & & 19 & 83,0 & 16 & 100,0 \\
\hline Distúrbio erétil & $15 / 15$ & 100,0 & & & 22 & 79,0 & 14 & 87,0 & 3 & 5,4 & & & $10^{*}$ & 100,0 \\
\hline Total de casos & 21 & & 14 & & 54 & & 16 & & 56 & & 23 & & 16 & \\
\hline
\end{tabular}

* Refere-se aos dez pacientes do sexo masculino; MMII: Membros inferiores

cone medular encontra-se acometido; espasticidade e nível sensitivo ( tato, dor) ocorrem em vigência de acometimento mais alto da medula.

De maneira geral, a paraparesia bilateral e os reflexos profundos abolidos ou reduzidos constituem os achados mais freqüentes ao exame neurológico ${ }^{94}$.

\section{ANÁLISE DO LIQUOR}

A análise do líquido cefalorraquidiano ( LCR) dos pacientes com MRE revela alterações inespecíficas: elevação discreta a moderada do conteúdo protéico em $95 \%$ dos casos ( média de $161,4 \pm 191,9 \mathrm{mg} / \mathrm{dl}$ ) , níveis normais de glicose, pleocitose em $91 \%$ dos casos (média de $91,9 \pm 113,8$ céls $/ \mathrm{mm}^{3}$ ) com predomínio de linfócitos e a presença de eosinófilos em 41\% dos $\operatorname{casos}^{35}$. Andrade Filho e cols ${ }^{7}$ observaram acentuada redução da celularidade liqüórica, com a melhora dos sintomas, mas, com persistência da hiperproteinorraquia em $66 \%$ dos casos.

Anticorpos anti-Schistosoma foram identificados em $85 \%$ dos LCR testados usando-se as técnicas de ELISA e/ou imunofluorescência indireta. A positividade da sorologia para o Schistosoma no LCR é considerada evidência de infecção esquistossomótica do SNC por vários autores, a despeito da ausência de estudo clínico neste sentido 5297790110 .

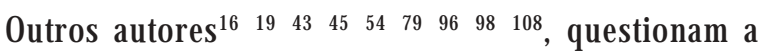
importância deste exame devido à falta de uniformidade na padronização do método, inexistência de estudo que comprove sua acurácia, e possibilidade de a sorologia liqüórica positiva representar apenas exposição prévia ou infecção extramedular, uma vez que há quebra da barreira hematoencefálica secundária ao processo inflamatório.
Além disso, a reação imunológica liquórica pode estar ausente mesmo em casos comprovados de MRE ${ }^{31}$.

\section{MÉTODOS DE IMAGEM}

A mielografia e a mielotomografia computadorizada revelam alterações em $63 \%$ dos casos de MRE que se caracterizam por aumento irregular do diâmetro medular e defeito de enchimento com ou sem bloqueio do canal medular, e espessamento de raízes nervosas da cauda eqüina ${ }^{13434749586899}{ }^{109}$. Aforma granulomatosa da doença medular é a mais freqüentemente diagnosticada por estes métodos de imagem porque causa aumento do volume medular.

Nos pacientes com doença de longa duração a atrofia da medula tem sido observada ${ }^{43}$.

A ressonância magnética (RM) mostrou alterações em praticamente todos os casos de MRE em que foi utilizada como método de estudo da medula espinhal, inclusive em casos em que a mielografia e/ou mielotomografia computadorizada não revelaram anormalidades ${ }^{29} 4065$.

$\mathrm{Na}$ verdade, há apenas dois estudos retrospectivos ${ }^{71}{ }^{78} \mathrm{e} u \mathrm{~m}$ prospectivo ${ }^{103}$ que utilizaram este método de imagem. Os outros contituem relatos isolados de casos ${ }^{13} 2529486593$. As principais alterações descritas na ressonância magnética são: aumento do diâmetro da medula espinhal e/ou de raízes da cauda eqüina nas imagens ponderadas em T1; hiperintensidade do sinal em T2 na região acometida, representando aumento do conteúdo de água (edema); e captação heterogênea de contraste (eventualmente homogênea) devido à quebra da barreira hematoencefálica, com pequenas áreas focais de acentuação mais intensa formando freqüentemente um padrão granular ( Figuras 2, 3 e 4). 


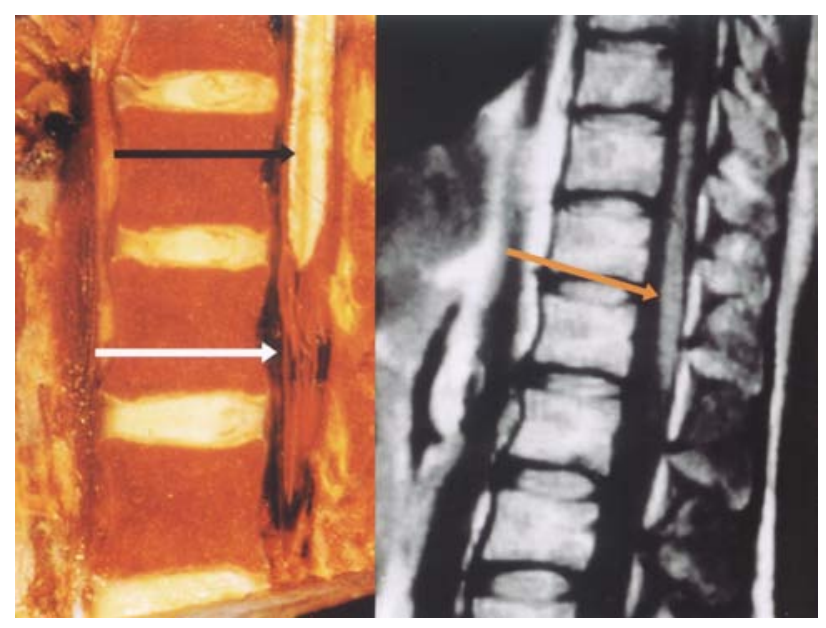

Figura 2 - Anatomia da medula espinhal normal. À esquerda, a seta preta aponta o cone medular e a branca a cauda eqüina em peça anatômica. À direita a seta laranja aponta o cone medular visto à ressonância magnética em imagem ponderada em T1.

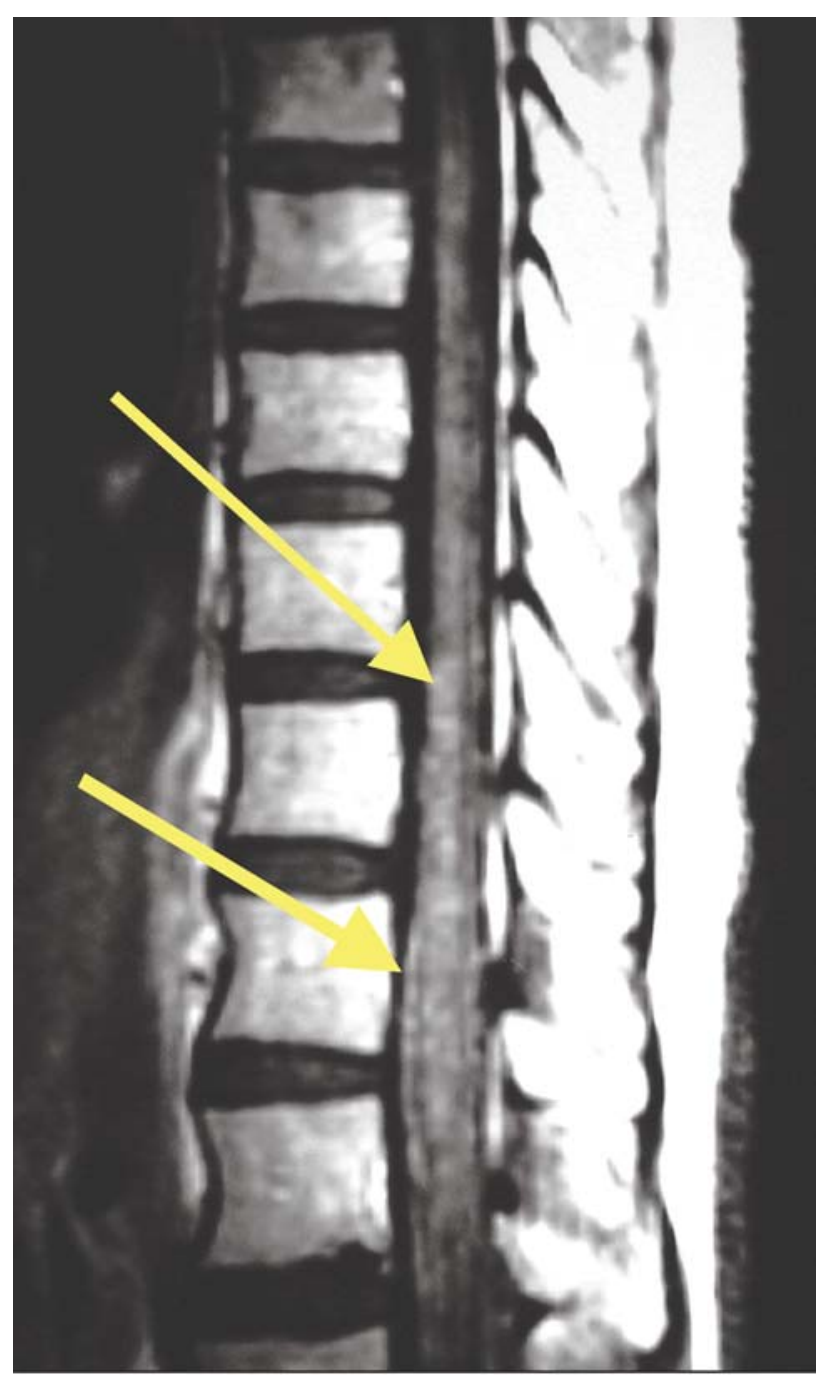

Figura 3 - Alargamento do cone medular e captação de contraste heterogênea e difusa, com aspecto granular (setas) em medula torácica baixa e cone medular em paciente com mielorradiculopatia esquistossomótica.

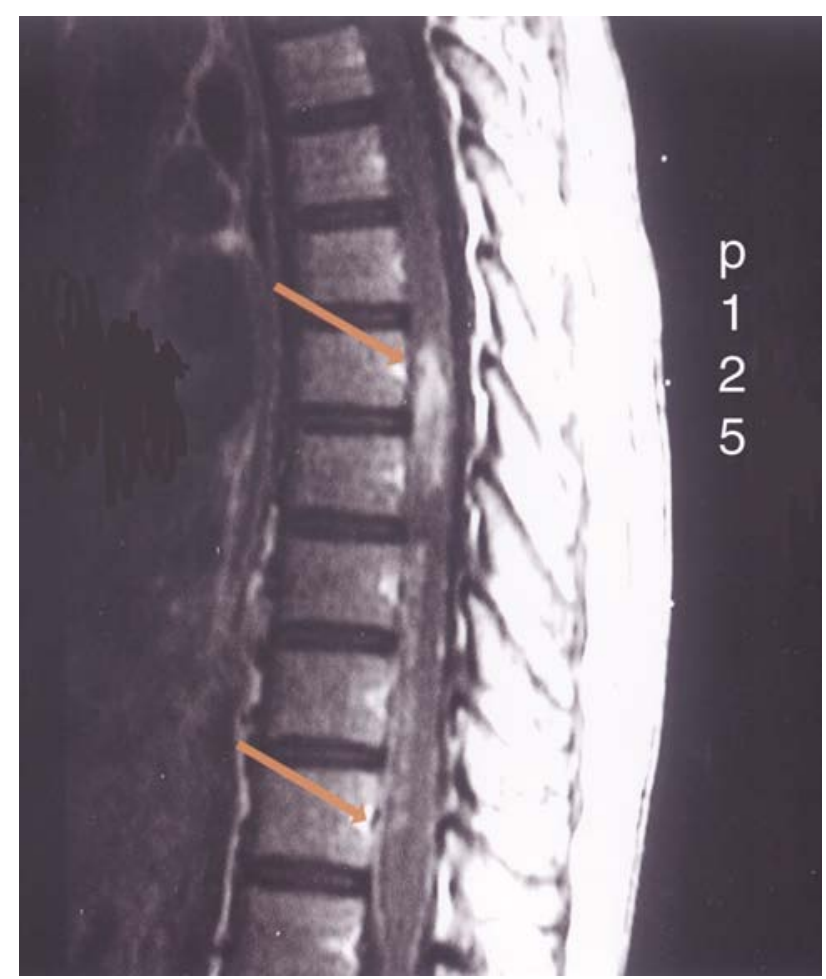

Figura 4 - Alargamento do cone medular (seta laranja inferior) e captação homogênea e circunscrita de contraste em medula torácica baixa ( seta laranja superior) em paciente com mielopatia esquistossomótica.

Portanto, trata-se de método propedêutico bastante sensível para a avaliação da MRE, apesar de as alterações diagnosticadas não serem específicas desta doençą22 40566692100.

Vale notar que Sanelli e colaboradores ${ }^{93}$, após o estudo de dois pacientes com esquistossomose cerebral e um com doença medular confirmados cirurgicamente, sugeriram um padrão de imagem à ressonância magnética que, apesar de não estar presente em todos os casos, quando observado, deve indicar o diagnóstico de esquistossomose do SNC. Ele se caracteriza pela captação central linear de contraste, cercada por múltiplos nódulos puntiformes, chamado de aspecto arborizado. Em 1998, Bennett e Provenzale ${ }^{13}$ já haviam descrito captação periférica de contraste com aspecto nodular da medula, entretanto, sem associação à captação central linear. Silva ${ }^{103}$ não encontrou padrão específico de mielorradiculopatia esquistossomótica na RM de 16 pacientes estudados prospectivamente.

As alterações observadas na ressonância magnética regridem paralelamente à melhora clínica do paciente após o tratamento com esquistossomicidas e corticoesteróides ${ }^{13} 29{ }^{22} 104$. Há casos de recidiva dos sintomas neurológicos após o tratamento, com normalização das imagens radiológicas, e com melhora após a re-introdução do mesmo tratamento. Ueki e cols ${ }^{109}$ relataram um caso de atrofia medular, sem alteração de sinal ou captação de contraste, com o mesmo esquema terapêutico.

Silva ${ }^{104}$, Van Leusen e Perquin ${ }^{111}$ descreveram normalização do diâmetro transverso da medula, porém, com manutenção de captação mínima de contraste após injeção de gadolíneo nas imagens por RM em sete pacientes tratados com 
praziquantel e prednisona e que evoluiram com acentuada melhora clínica.

\section{DEMONSTRAÇÃ0 DE EXPOSIÇÃ0 À ESQUISTOSSOMOSE}

Os ovos de Schistosoma foram encontrados nas fezes, urina e/ou tecido (mucosa retal, mucosa vesical, pele ou tecido medular) em 203 ( 88,3\%) dos 231 casos revistos por Ferrari $^{35}$, em 1999. Nos 28 casos restantes, a demonstração de exposição à esquistossomose foi indireta, baseada em pesquisa de anticorpos no soro ou em dados epidemiológicos. A sorologia foi realizada em 78 (33,8\%) pacientes e mostrouse positiva em 74 (94,9\%).

A busca de anticorpos contra antígenos do Schistosoma no soro para o diagnóstico de infecção apresenta limitações devido à reação cruzada com outros antígenos, principalmente de outros helmintos, e à dificuldade em se diferenciar entre infecção ativa de contato prévio com o parasita, pois os anticorpos podem permanecer no soro por longos períodos mesmo após o tratamento curativo ${ }^{74}$.

\section{TRATAMENTO E PROGNÓSTICO}

0 tratamento da MRE se faz com esquistossomicidas, corticoesteróides e/ou cirurgia ( Figura 5).

Através da destruição do verme adulto, os esquistossomicidas interrompem a produção de ovos e evitam a reação inflamatória no $\mathrm{SNC}^{43} 4798109$.

Descreveu-se melhora clínica nos casos tratados exclusivamente com estas drogas ${ }^{6} 4143 \quad 56 \quad 69{ }^{70}$. A rápida e acentuada melhora observada com 0 uso dos esquistossomicidas levou à crença de que estas drogas teriam outro mecanismo de ação associado: ovicida e/ou moduladora da resposta imune e inflamatória ${ }^{62}$.

Os corticoesteróides agem reduzindo a atividade inflamatória e, como consequêencia, diminuem a compressão e destruição de tecido nervoso ${ }^{25}$. Observou-se melhora acentuada e imediata após a introdução de corticoesteróides isoladamente em alguns pacientes, inclusive com o desaparecimento das alterações observadas na mielografia.

0 tempo de utilização da corticoterapia não se encontra definido ${ }^{35} 54$ 71. Porém, a retirada desta droga não só precoce

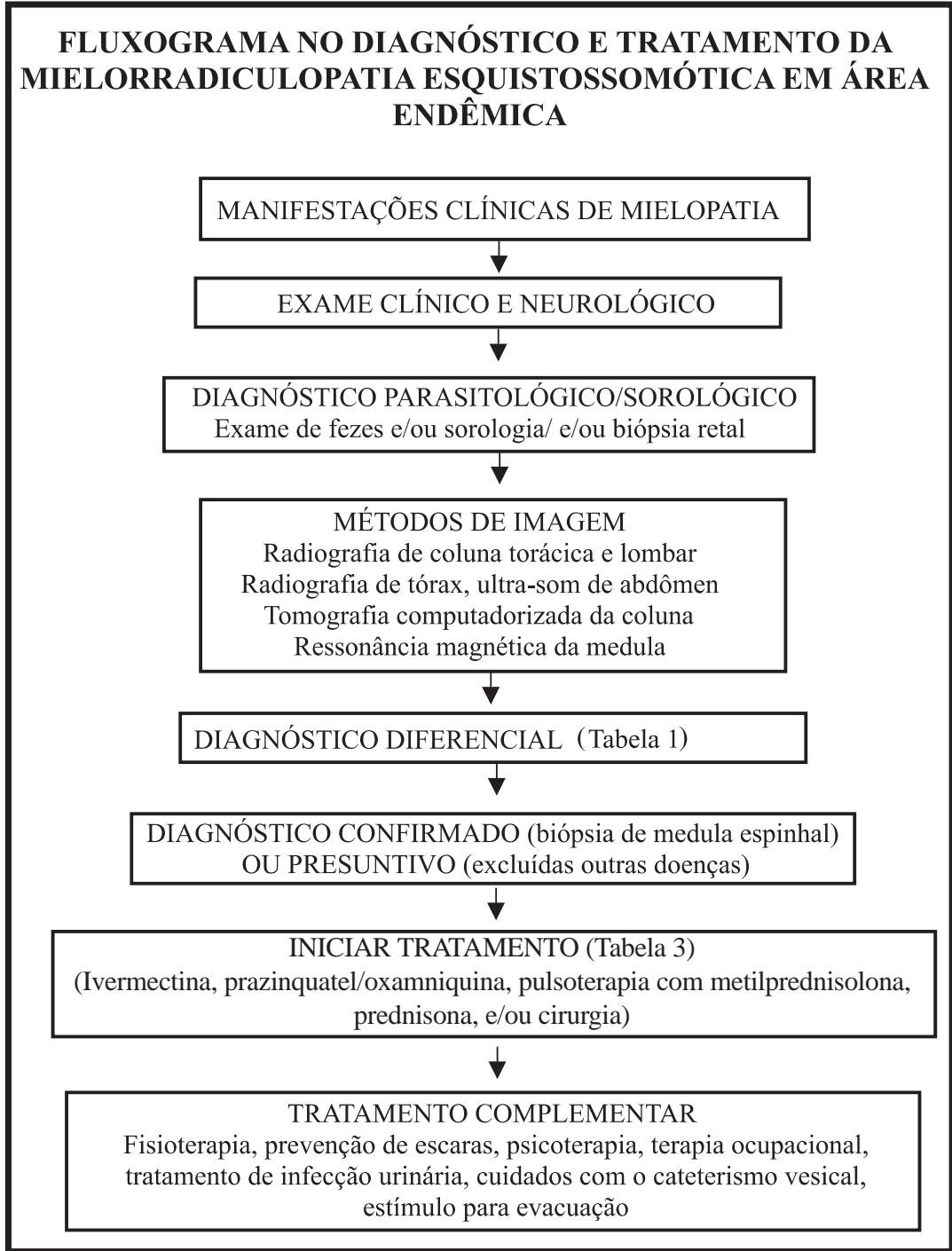

Figura 5 - Fuxograma no diagnóstico e tratamento da mielorradiculopatia esquistossomótica em área endêmica. 
como também até $06^{0}$ mês de tratamento, pode associar-se à recidiva das manifestações neurológicas.

As doses de prednisona utilizadas variam em média de $20 \mathrm{mg} /$ dia a $2 \mathrm{mg} / \mathrm{kg} /$ dia, por um período entre 7 dias e 12 meses ( Tabela 3).

A cirurgia deve ser reservada para pacientes com paraplegia aguda e bloqueio do LCR ${ }^{17}{ }^{31}$, para os que apresentam piora clínica, a despeito do tratamento conservador, e menos freqüentemente com objetivos diagnósticos. Os pacientes que sofreram intervenção cirúrgica apresentaram índices de melhora mais baixos, independentemente de terem ou não recebido tratamento

Tabela 3 - Esquema terapêutico, usado pelos autores, no tratamento da mielorradiculopatia esquistossomótica.

\begin{tabular}{ll}
\hline Droga & \multicolumn{1}{c}{ Esquema terapêutico } \\
\hline Ivermectina & $\begin{array}{l}\text { 200 microgramas/kg de peso, dose única: dois comprimidos } \\
\text { (de } 6 \mathrm{mg}) \text { em dose única para tratamento de possível } \\
\text { estrongiloidíase em adultos }\end{array}$ \\
\hline Praziquantel & $\begin{array}{l}\text { 50mg/kg de peso, dividido em duas doses com intervalo de quatro } \\
\text { horas para tratamento da esquistossomose mansoni }\end{array}$ \\
\hline Pulsoterapia com & $\begin{array}{l}\text { 15mg/kg de peso/dia: dose máxima de 1g } \\
\text { endovenoso por cinco dias }\end{array}$ \\
\hline Pretilprednisolona & $\begin{array}{l}1 \mathrm{mg} / \mathrm{kg} \text { de peso, dose única, pela manhã durante seis meses, } \\
\text { com retirada lenta }\end{array}$ \\
\hline
\end{tabular}

clínico após a cirurgia, apesar de relatos de evolução favorável em alguns casos. Os procedimentos se limitam à descompressão, biópsia e liberação de raízes nervosas.

Noventa e cinco por cento dos pacientes com MRE que não recebem tratamento morrem ou não apresentam melhora clínica. Na Tabela 4 demonstra-se a importância da terapêutica nesta doença. 0 estudo de Silva ${ }^{103}$ sugere que a instituição da terapêutica, mesmo tardia, após 12 meses de início do quadro neurológico, pode se associar a melhora neurológica.

A Tabela 5 resume dados que demonstram a importância da associação do esquistossomicida com os corticoesteróides no tratamento da mielopatia. Esta associação se relaciona à melhor resposta terapêutica. Um achado consistente é a rapidez do início da melhora motora, sensitiva e de controle esfincteriano $0^{25} 4383$.

0 tratamento adequado da MRE deve ser multidisciplinar, envolvendo a participação de fisioterapeutas, enfermeiros, psicólogos, clínicos, neurologistas e terapeutas ocupacionais. A infecção do trato urinário mostra-se comum e deve ser investigada. Todo esforço deve ser mantido para se evitar 0 desenvolvimento de escaras nos pacientes acamados.

Os casos de mielopatia resumidos a seguir servem de exemplo de apresentação clínica da esquistossomose da medula espinhal e de seu diagnóstico diferencial.

Tabela 4 - Resposta terapêutica dos pacientes com mielorradiculopatia esquistossomótica em seis estudos clínicos.

\begin{tabular}{|c|c|c|c|c|c|c|c|c|c|c|c|c|}
\hline \multirow[t]{2}{*}{ Resposta terapêutica } & \multicolumn{2}{|c|}{$\begin{array}{c}\text { Peregrino } \\
\text { (1988) }\end{array}$} & \multicolumn{2}{|c|}{$\begin{array}{l}\text { Haribhai } \\
\text { (1991) }\end{array}$} & \multicolumn{2}{|c|}{$\begin{array}{c}\text { Andrade Filho } \\
\text { (1996) }\end{array}$} & \multicolumn{2}{|c|}{$\begin{array}{l}\text { Santos } \\
\text { (2001) }\end{array}$} & \multicolumn{2}{|c|}{$\begin{array}{l}\text { Nobre } \\
\text { (2001) }\end{array}$} & \multicolumn{2}{|c|}{$\begin{array}{c}\text { Silva } \\
(2002)\end{array}$} \\
\hline & $\mathrm{n}^{0}$ & $\%$ & $\mathrm{n}^{0}$ & $\%$ & $\mathrm{n}^{0}$ & $\%$ & $\mathrm{n}^{0}$ & $\%$ & $\mathrm{n}^{0}$ & $\%$ & $\mathrm{n}^{0}$ & $\%$ \\
\hline Recuperação & 19 & 90,5 & & & & & & & & & & \\
\hline completa & 13 & 61,9 & & & & & & & 5 & 21,7 & 3 & 18,7 \\
\hline parcial & 6 & 28,6 & & & & & & & & & & \\
\hline sem limitação funcional & & & & & & & & & 13 & 56,5 & 9 & 56,3 \\
\hline com limitação funcional & & & & & & & & & & & 4 & 25,0 \\
\hline sem outra especificação & & & 11 & 78,6 & 12 & 75,0 & 35 & 62,5 & & & & \\
\hline Recuperação c/ limitação funcional ou sem recuperação & & & & & & & & & 4 & 17,4 & & \\
\hline Ausência de recuperação & 2 & 9,5 & 3 & 21,4 & 4 & 25,0 & 14 & 25,0 & & & & \\
\hline Sem informação & & & & & & & 7 & 12,5 & & & & \\
\hline Total & 21 & & 14 & & 16 & & 56 & & 22 & & 16 & \\
\hline
\end{tabular}

Tabela 5 - Tratamento dos casos de mielorradiculopatia esquistossomótica em seis estudos clínicos.

\begin{tabular}{|c|c|c|c|c|c|c|c|c|c|c|c|c|}
\hline \multirow[t]{2}{*}{ Tratamento } & \multicolumn{2}{|c|}{$\begin{array}{c}\text { Peregrino } \\
\text { (1988) }\end{array}$} & \multicolumn{2}{|c|}{$\begin{array}{c}\text { Haribhai } \\
\text { (1991) }\end{array}$} & \multicolumn{2}{|c|}{$\begin{array}{l}\text { Andrade Filho } \\
\text { (1996) }\end{array}$} & \multicolumn{2}{|c|}{$\begin{array}{l}\text { Santos } \\
\text { (2001) }\end{array}$} & \multicolumn{2}{|c|}{$\begin{array}{l}\text { Nobre } \\
\text { (2001) }\end{array}$} & \multicolumn{2}{|c|}{$\begin{array}{c}\text { Silva } \\
\text { (2002) }\end{array}$} \\
\hline & $\mathrm{n}^{0}$ & $\%$ & $\mathrm{n}^{0}$ & $\%$ & $\mathrm{n}^{0}$ & $\%$ & $\mathrm{n}^{0}$ & $\%$ & $\mathrm{n}^{0}$ & $\%$ & $\mathrm{n}^{0}$ & $\%$ \\
\hline \multicolumn{13}{|l|}{ Esquistossomicida } \\
\hline exclusivamente & & & 3 & 21,4 & & & 1 & 1,8 & & & & \\
\hline + corticoesteróide* & 21 & 100,0 & 9 & 64,3 & 16 & 100,0 & 41 & 73,2 & 23 & 100,0 & 16 & 100,0 \\
\hline \multicolumn{13}{|l|}{ + cirurgia* } \\
\hline \multicolumn{13}{|c|}{ + corticoesteróide + cirurgia* } \\
\hline Cirurgia exclusivamente & & & 2 & 14,3 & & & & & & & & \\
\hline Corticoesteróide exclusivo & & & & & & & 12 & 21,4 & & & & \\
\hline Nenhum & & & & & & & 2 & 3,6 & & & & \\
\hline Total & 21 & & 14 & & 16 & & 56 & & 23 & & 16 & \\
\hline
\end{tabular}

*associado ao esquistossomicida 


\section{PRIMEIRO CASO}

Opaciente, de 7 anos de idade, residente em Teófilo Otoni, queixou-se de dormência na nádega esquerda, de início havia 40 dias. Nos últimos 15 dias notou dor lombar de intensidade crescente ("dor nos rins"), dormência na perna esquerda e apresentou retenção urinária com sensação de calor no corpo. 0 médico que 0 examinou notou rigidez de nuca, fraqueza na perna esquerda e anotou temperatura axilar de $37,8^{\circ} \mathrm{C}$. 0 hemograma revelou leucocitose com desvio à esquerda. Olíquor revelou elevação de proteínas e de células e não seisolou agente bacteriano. Como na ocasião, em sua cidade, havia casos de meningite bacteriana, suspeitou-se da doença e a criança foi tratada com penicilina e corticoesteróides. Houve melhora rápida do quadro clínico com o desaparecimento da retenção urinária. 0 exame sorológico do líquor mostrou-se positivo para esquistossomose (imunofluorescência com antígeno de ovo). Ele recebeu, então, praziquantel ( $40 \mathrm{mg} / \mathrm{kg}$ de peso/dia, por dois dias). Sete dias mais tarde suspendeu-se 0 corticoesteróide e a criança voltou a apresentar retenção urinária, dor lombar e não conseguia andar. Aurina passou a ser retirada com cateterismo vesical de 6 em 6 horas. Em Belo Horizonte, notou-se ao exame clínico hepatoesplenomegalia e a ressonância magnética da medula espinhal revelou aumento volumétrico da medula torácica baixa e do cone medular com captação de contraste (níveis T11, T12 e L1) (Figura 6). 0 paciente recebeu novo tratamento com praziquantel e ivermectina e iniciou-se, no dia seguinte, prednisona na dose de $20 \mathrm{mg}$ por dia $(1 \mathrm{mg} / \mathrm{kg} / \mathrm{dia})$. Houve melhora rápida do quadro clínico e 15 dias depois ele andava sem apoio e urinava espontaneamente. Ele recebeu também antibiótico para infecção urinária. 0 tratamento com corticoesteróides foi mantido por quatro meses e, a seguir, retirado lentamente. Não houve recidiva do quadro clínico. Um ano depois a criança estava bem.

\section{SEGUND0 CASO}

Opaciente, de 59 anos deidade, residente em Teófilo Otoni, estava bem até 15 dias antes da internação, quando começou a apresentar dor ao urinar, seguida de retenção urinária e perda de força em membros inferiores. Ele procurou médico em sua cidade que requisitou exame de urina, fezes e radiografia simples da coluna lombar. Ele foi tratado com praziquantel e corticoesteróides com o diagnóstico presuntivo de mielite esquistossomótica e, a seguir, encaminhado a Belo Horizonte para dar sequiência à propedêutica e tratamento. 0 pacientefoi hospitalizado com cateter vesical de demora, febre alta e hipotensão arterial, com o diagnóstico de sepse secundária à infecção urinária. As hemoculturas revelaram a presença de Escherichia coli em três amostras. Ele foi tratado com antibióticos e hidratação parenteral com melhora rápida do quadro infeccioso. 0 quadro neurológico persistiu com retenção urinária, paraplegia flácida e dor lombar. A ressonância magnética da coluna revelou a presença de lesão tumoral comprimindo a medula espinhal (Figura 7). Os exames complementares confirmaram a presença de tumor de próstata com metástases para vários órgãos ( ver cintilografia na Figura 7). Ele foi tratado com orquiectomia, radioterapia da coluna vertebral, morfina e corticoesteróides e apresentou discreta melhora, com movimentação ativa da perna esquerda. Recebeu alta hospitalar, 30 dias depois, para controle domiciliar.

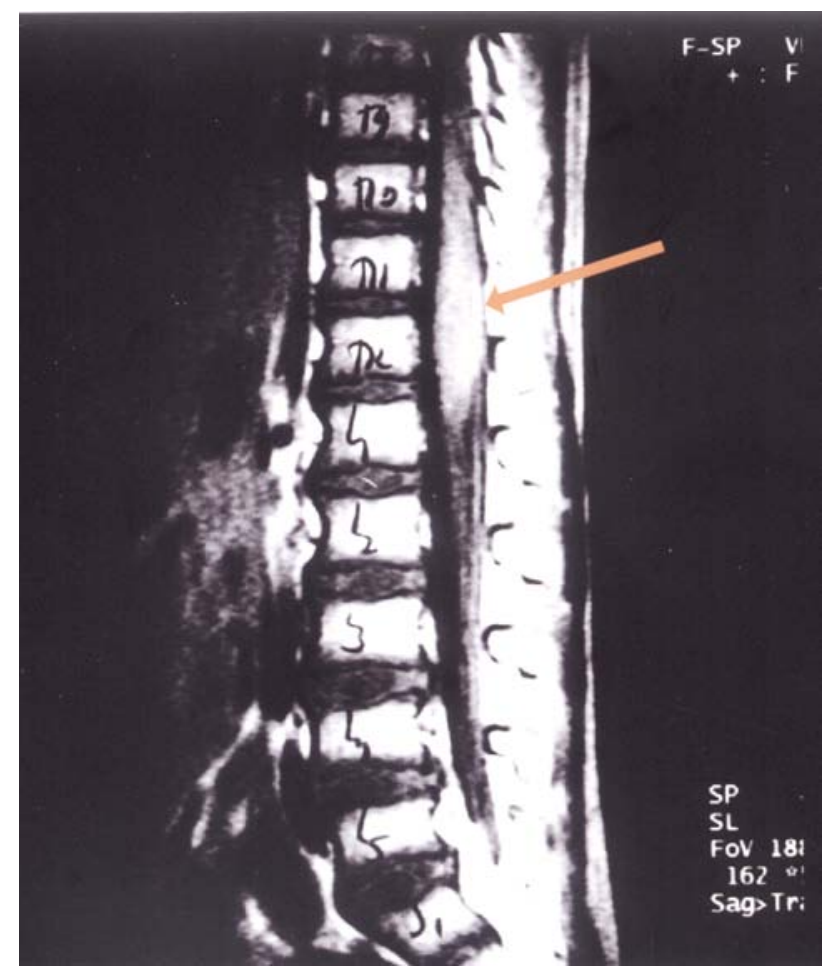

Figura 6 - Aumento volumétrico do cone medular e medula torácica baixa com acentuação homogênea do sinal ( seta) após injeção endovenosa de contraste em paciente com mielopatia esquistossomótica.

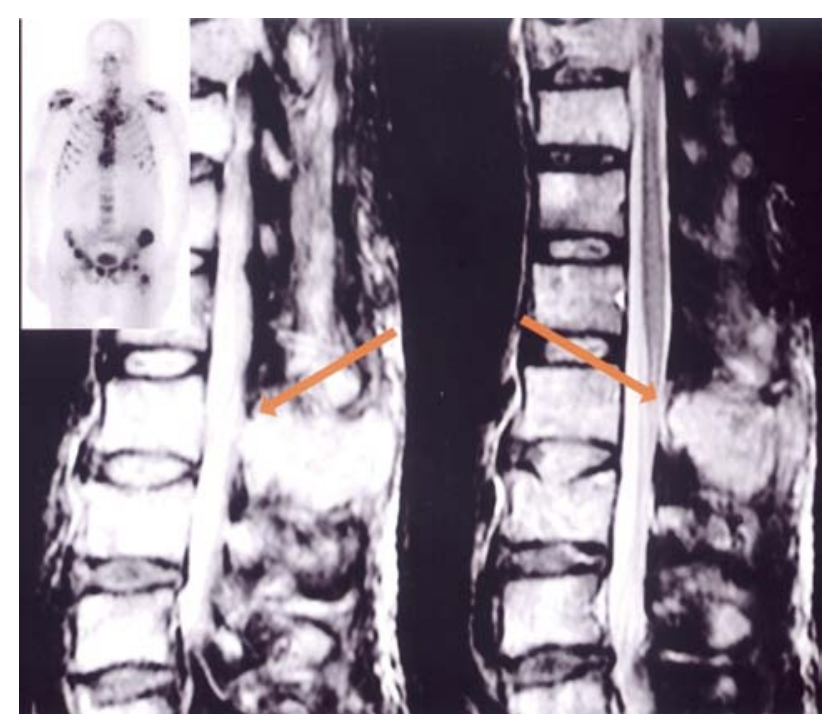

Figura 7 - Compressão da medula espinhal por metástase de tumor de próstata para a coluna vertebral ( setas). No destaque veja a cintilografia óssea (as áreas captantes - escuras - representam pontos de metástases). 


\section{REFERÊNCIAS BIBLIOGRÁFICAS}

1. Abbott PH, Spencer H. Transverse myelitis due to ova of Schistosoma mansoni. Transactions of the Royal Society of Tropical Medicine and Hygiene 47: 221-223, 1953.

2. Al Deeb SM, Yaqub BA, Bruyn GW, Biary NM. Acute transverse myelitis: a localized form of postinfectiuos encephalomyelitis. Brain 120:1115-1122, 1997.

3. Alves W. The distribution of schistosoma eggs in human tissues. World Health Organization Series 18: 1092-1097, 1958.

4. Amaral RS, Porto MAS. Evolução e situação atual do controle da esquistossomose no Brasil. Revista da Sociedade Brasileira de Medicina Tropical 27 ( supl III) : 73-90, 1994.

5. Andrade AN. Neuroesquistossomose. Arquivos de Neuropsiquiatria 44: 275-279, 1986.

6. Andrade Filho AS, Queiroz AC. Meningorradiculite esquistossomótica: Estudo clínico-laboratorial de três casos tratados. Arquivos de Neuropsiquiatria 49: 80-82, 1991

7. Andrade Filho AS, Reis MG, Souza AL, Martins ER, Santos SRS, Ancilon M, Lima JMPF, Queiroz AC, Guimarães MGM, Moreno-Carvalho A0, Rêgo MF Neuroesquistossomose mansônica: aspectos clínicos, laboratoriais e terapêuticos. Arquivos de Neuropsiquiatria 54: 232-237, 1996.

8. Andrews P, Thomas H, Pohlke R, SeubertJ. Praziquantel. Medical Research Reviews 3: 147-200, 1983 .

9. Asano NMJ. Neuroesquistossomose: Aspectos clínicos, laboratoriais e de imunodiagnóstico. Tese, Universidade Federal de Pernambuco, Recife, $\mathrm{PE}, 1992$.

10. Azevedo Filho HRC, Hazin SMV, Melo RV, Carneiro Filho GS, Brito DMM. Mielopatia esquistossomótica. Arquivos Brasileiros de Neurocirurgia 6: 123-129, 1987

11. Bac DJ, Teichler MJ, Jonker LC, Van Der Merwe CF. Schistosomiasis in ectopic or unusual sites: Areport of 5 cases. South African Medical Journal 72: 717-718, 1987.

12. Batson OV. The function of the vertebral veins and their role in the spread of metastases. Annals of Surgery 112: 138-149, 1940.

13. Bennett $G$, Provenzale JM. Schistosomal myelitis findings at MR imaging. European Journal of Radiology 27: 268-270, 1998.

14. Bird AV. Acute spinal schistosomiasis. Neurology 14: 647-656, 1964.

15. Bird AV. Spinal cord complications of bilharziasis. South African Medical Journal 39: 158-162, 1965

16. Bissessur S, Minderhound JM. Two cases of schistosomiasis. Clinical Neurology and Neurosurgery 87: 213-217, 1985.

17. Bloom K, Freed MM. Paraplegia from schistosomiasis. Paraplegia 28: 455459, 1990.

18. Blunt SB, Boulton J, Wise R. MRI in schistosomiasis of conus medullaris and lumbar spinal cord (letter). Lancet 341: 557, 1993.

19. Boyce TG. Acute transverse myelitis in a 6-year-old girl with schistosomiasis. Pediatric Infectious Disease Journal 9: 279-284, 1990.

20. Braga, BP, da Costa Junior LB, Lambertucci JR. Magnetic resonance imaging of cerebellar schistosomiasis mansoni. Revista da Sociedade Brasileira de Medicina Tropical 36: 635-636, 2003.

21. Bruijning CFA. The mechanism of the passage of the Schistosoma mansoni egg through the wall of the blood vessel. Tropical and Geographic Medicine 16: 159-163, 1964.

22. Brunberg JA, Di Pietro MA, Venes JL, Dauser RC, Muraszko KM, Berkey GS, D'Amato CJ, Rubin JM. Intramedullary lesions of the pediatric spinal cord: correlation of findings from MR imaging, intraoperative sonography, surgery and histologic study. Radiology 181: 573-579, 1991

23. Budzilovich GN, Most H, Feigin I. Pathogenesis and latency of spinal cord schistosomiasis. Archives of Pathology 77: 383-388, 1964.

24. Case Records of the Massachusetts General Hospital. Weekly clinicopathological exercises. Case 21-1985. A 21-year-old man with fever, diarrhea, and weakness of the legs during a sojourn in Kenya (clinical conference). New England Journal of Medicine 312: 1376-1383, 1985.

25. Case Records of the Massachusetts General Hospital. Weekly clinicopathological exercises. Case 4-1996. A 40-year-old woman with the rapid onset of flaccid paraplegia ( clinical conference). New England Journal of Medicine 334: 382-389, 1996.

26. Cosnett, Van Dellen JR. Schistosomiasis (bilharzia) of the spinal cord: Case reports and clinical profile. Quarterly Journal of Medicine 61: 1131 . 1139, 1986

27. Costa Junior LB, Lemos SP, Lambertucci JR. Magnetic resonance imaging of cysticercosis of the cauda equina. Revista da Sociedade Brasileira de Medicina Tropical 36: 761-762, 2003.

28. Day HB, Kenawy MR. A case of bilharzial myelitis. Transactions of the Royal Society of Tropical Medicine and Hygiene 30: 223-224, 1936. Apud: Faust $\mathrm{EC}$. An inquiry into the ectopic lesions in schistosomiasis. American Journal of Tropical Medicine 28: 175-199, 1948

29. Dupuis MJM, Atrouni S, Dooms GC, Gonrrette RE. MRimaging of Schistosomal myelitis. American Journal of Neuroradiology 11: 782-783, 1990.

30. Efthimiou J, Denning D. Spinal cord disease due to Schistosoma mansoni successfully treated with oxamniquine. British Medical Journal (Clin Res Ed) 288: 1343-1344, 1984

31. El-Banhawy A, Elwan 0, Taher Y. Bilharzial granuloma of conus medullaris and cauda equina. Paraplegia 10: 172-180, 1972.

32. Elkhayat RAAM, Girgis M. Bilharzial granuloma of the conus: Case report. Neurosurgery 32: 1022-1024, 1993.

33. Faust EC. An inquiry into the ectopic lesions in schistosomiasis. American Journal of Tropical Medicine 28: 175-199, 1948.

34. Ferguson AR. The lesions of on bilharzial disease. Glasgow Medical Journal 79: 14-23, 1913. Apud: Faust EC. An inquiry into the ectopic lesions in schistosomiasis. American Journal of Tropical Medicine 28: 175-199, 1948.

35. Ferrari TCA. Spinal Cord Schistosomiasis: A report of 2 cases and review emphasizing clinical aspects. Medicine 78: 176-190, 1999.

36. Galvão ACR. Mielopatias Esquistossomóticas: Aspectos Clínicos e Laboratoriais. Tese, Faculdade de Medicina da Universidade de São Paulo, São Paulo, SP, 1983.

37. Gama C. Compression granuloma of spinal cord caused by Schistosoma mansoni ova; epiconus, conus medullaris, cauda equine: Report of a case. Journal of the International College of Surgery 19: 665-674, 1953.

38. Gellido CL, Onesti S, Llena J, Suarez M. Spinal schistosomiasis. Neurology 54: 527, 2000.

39. Ghaly AF, El-Banhawy A. Schistosomiasis of the spinal cord. Journal of Pathology 111: 57-60, 1973

40. Goffete S, Dardenne G, Dupuis M, Donnay M, Duprez T. Schistosomal myelopathy: relevance and limits of contrast enhanced magnetic resonance imaging in spinal cord infections. Acta Neurologica Belga 98: 289-291, 1998.

41. Gottlieb F. Schistosomiasis haematobium infections presenting as central nervous system lesions. American Journal of Medicine 97: 101-103, 1994.

42. Grand S, Movet E, Le Bas JF. Case Report: Spinal Cord Schistosomiasis: MRI Findings. Clinical Radiology 51: 739-740, 1996.

43. Haribhai HC, Bhigjee AI, Bill PLA, Pammenter MD, Modi G, Hoffmann M, Kelbe C, Becker P. Spinal cord schistosomiasis: a clinical, laboratory and radiologic study, with a note on therapeutic aspects. Brain 114: 709-726, 1991.

44. Harrison LH, Vaz B, Taveira DM, Quinn TC, Gibbs CJ, De Souza SH, Mc Arthur JC, Schechter M. Myelopathy among Brazilians coinfected with human T-cell lymphotropic virus type I and HIV. Neurology 48: 13-18, 1997.

45. Heller HM, Carnevale NT, Steigbiel RT. Varicella Zoster virus transverse myelitis without cutaneous rash. American Journal of Medicine 88: 550-551, 1990.

46. Houpis J, Oexmann, Martin J, Jacobi G, Readon J, Waterman G. Acute schistosomiasis with transverse myelitis in American students returning from Kenya. Morbidity and Mortality Weekly Report 33: 445-447, 1984.

47. Joubert J, Fripp PJ, Hay IT, Davel GH, Van Graan ESJ. Schistosomiasis of the spinal cord - underdiagnosed in South Africa? South African Medical Journal 77: 297-299, 1990 
48. Junker J, Eckardt L, Husstedt I. Cervical intramedullar schistosomiasis as a rare cause of acute tetraparesis. Clinical Neurology and Neurosurgery 103: 39-42, 2001.

49. Kerr RSC, Marks SM, Sheldon PWE, Teddy PJ. Schistosoma mansoni in the spinal cord: a correlation between operative and radiological findings. Journal of Neurology and Psychiatry 50: 822-823, 1987.

50. Lacoste D, Delmas M, Longy M, Denien JD, Le Bras M, Moretti G. Les Myelopathies Bilharziennes: A propos d'une observation. Medicine Tropicale 40: 295-300, 1980.

51. Lambertucci JR. Schistosoma mansoni: pathological and clinical aspects. In: Jordan P, Webbe G, Sturrock RF (eds) Human Schistosomiasis, Cab International, Wallingford, 1993.

52. Lambertucci JR, Barraviera B. Esquistossomose mansônica. Estudo Clínico. Jornal Brasileiro de Medicina 67: 59-100, 1994.

53. Lambertucci JR, Rocha RS, Carvalho OS, Katz N. A esquistossomose mansoni em Minas Gerais. Revista da Sociedade Brasileira de Medicina Tropical 20: 47-52, 1987

54. Lambertucci JR, Serufo JC, Gerspacher-Lara R, Rayes AAM, Teixeira R, Nobre V, Antunes CMF. Schistosoma mansoni: assessment of morbidity before and after control. Acta Tropica 77: 101-109, 2000

55. Lechtenberg R, Vaida GA. Schsitosomiasis of the spinal cord. Neurology 27: 55-59, 1977.

56. Leite CC, Souza AF, Valente M, Araújo MAN, Jinkins JR. Clinics in Diagnostic Imaging. Singapore Medical Journal 41: 417-419, 2000.

57. Liblau R, Chiras J, Orssaud C, Dormont D, Dudos H, Gentilini M. Infarctus medullaire dans le territoire spinal anterieur en rapport possible avec une bilharziose. Neurologie (Paris) 147: 605-608, 1991.

58. Liu LX. Spinal and cerebral schistosomiasis. Seminars in Neurology 13: 189-200, 1993

59. Livramento JA, Machado LR, Silva LC, Spina-França A. Síndrome do líquido cefalorraqueano na neuroesquistossomose. Arquivos de Neuropsiquiatria 45: 372-377, 1985.

60. Livramento JA, Machado LR, Spina-França A. Sinalização do líquido cefalorraqueano em doenças inflamatórias crônicas do sistema nervoso central. Arquivos de Neuropsiquiatria. 44: 351-358, 1986.

61. Luyendijk W, Lindeman J. Schistosomiasis (bilharziasis) mansoni of the spinal cord simulating an intramedullary tumor. Surgical Neurology 4: 457-460, 1975

62. Madwar MA, El-Fekhakh EA, Montasser MR, Hussein MM, Ahmed MSE, Ahmed SEM. Effect of oxamniquine and praziquantel on cell-mediated immunity in intestinal bilharziasis. Journal of the Egyptian Society of Parasitology 13: 277-283, 1983.

63. Marcial-Rojas RA, Fiol RE. Neurological complications of schistosomiasis: review of the literature and report of two cases of transverse myelitis due to Schsitosoma mansoni. Annals of Internal Medicine 59: 215-230, 1963.

64. Marra B. Aspects evolutifs d'une myelopathie bilharzienne a Schistosoma mansoni. Medicine Tropicale 53: 455-470, 1993.

65. Masson C, Rey A, Ast G, Cambier J, Masson M. Schistosomiase médullaire: Apport de l'imagine par résonance magnétique. Presse Medicale 19: 12231224,1990

66. Merine D, Wang H, Kumar AJ, Zinreich SJ, Rosenbaum AE. CT myelography and MR imaging of acute transverse myelitis. Journal of Computed Assisted Tomography 11: 606-608, 1987.

67. Molyneux ME, Galatius-Jensen F. Successful drug treatment of schistosomal myelopathy: a case report. South African Medical Journal 54: 871-872, 1978.

68. Moraes-Júnior LC, Maciel DRK, Tamburus WM, Wanderley ECFO, Ballalai H, Câmara ML. Granuloma esquistossomótico medular: registro de um caso. Arquivos de Neuropsiquiatria 42: 277-281, 1984.

69. Nazer H, Hugosson C, Posas H. Transverse myelitis in a child with Down's syndrome and schistosoma colitis. Annals of Tropical Pediatrics 13: 353357, 1993.

70. Neves J, Marinho RP, Araújo PK, Raso P. Spinal cord complications of acute schistosomiasis mansoni. Transactions of the Royal Society of Tropical Medicine and Hygiene 67: 782-792, 1973.
71. Nobre V, Silva LCS, Ribas JG, Rayes A, Serufo JC, Lana-Peixoto MA, Marinho RFZ, Lambertucci JR. Schistosomal Myeloradiculopathy due to Schistosoma mansoni: Report on 23 Cases. Memórias do Instituto Oswaldo Cruz 96: 137-141, 2001

72. Norfray JF, Schlachter L, Heiser WJ, Weinberg PE, Jerva MJ, Wizgrid JP. Schistosomiasis of the spinal cord. Surgical Neurology 9: 68-71, 1978.

73. Odeku EL, Lucas AO, Richard DR. Intramedullary spinal cord schistosomiasis: Case Report. Journal of Neurosurgery 29: 417-423, 1968.

74. Pammenter MD, Epstein SR, Rees RT. Cross reactions in the immunodiagnosis of schistosomiasis and cysticercosis by a cerebrospinal fluid enzyme-linked immunosorbent assay. Transactions of the Royal Society of Tropical Medicine and Hygiene 86: 51-52, 1992.

75. Pammenter MD, Haribhai HC, Epstein SR, Russouw EJ, Bhigjee AI, Bill PLA. The value of immunological approaches to the diagnosis of schistosomal myelopathy. American Journal of Tropical Medicine and Hygiene 44: 329-335, 1991.

76. Pannier S, Got C, Bourgeois-Gavardin M, Lacert P, Piera JB, Grossiord A. Paraplégie et bilharziose: a propos de quatre observations ( don't deux de myélite bilharzienne certaine). Revue de Neurologie (Paris) 133: 165 173, 1977.

77. Peregrino AJP, Oliveira SP, Porto CA, Santos LA, Menezes EE, Silva AP, Brito AL, Pinheiro SP, Pinheiro S, Dias AB. Meningomielorradiculite por Schistosoma mansoni: Protocolo de investigação e registro de 21 casos. Arquivos de Neuropsiquiatria 46: 49-60, 1988.

78. Peregrino AJP, Puglia PMK, Baracheschi LA, Hirata MTA, Brotto MWI Nóbrega JPS, Scaff M. Diagnosis of schistosomiasis of the spinal cord: contribution of magnetic resonance imaging and electroneuromyography. Arquivos de Neuropsiquiatria 60: 597-602, 2002.

79. Pittella JEH. Neuroschistosomiasis. Brain Pathology 7: 649-662, 1997.

80. Pittella JEH. The relation between involvement of the central nervous system in Schistosomiasis mansoni and the clinical forms of the parasitosis. A review. Journal of Tropical Medicine and Hygiene 94: 15-21, 1991.

81. Pittella JEH, Gusmão SN, Carvalho GT, Silveira RL, Campos GL. Tumoral form of cerebral schistosomiasis mansoni: a report of four cases and a review of the literature. Clinical Neurology and Neurosurgery 98: 15-20, 1996.

82. Pittella JEH, Lana-Peixoto MA. Brain involvement in hepatosplenic schistosomiasis mansoni. Brain 104: 621-632, 1981

83. Polam S, Di John D, De Carlo R, Strauss R, Vadde N. A snail tale. The Pediatric Infectious Disease Journal 18: 173-174, 1999.

84. Queiros AC. 0 envolvimento do sistema nervoso central na esquistossomose mansônica. Revista de Patologia Tropical 3: 255-261, 1974

85. Queiroz LS, Nucci A, Facure NO, Facure JJ. Massive spinal cord necrosis in schistosomiasis. Archives of Neurology 36: 517-519, 1979.

86. Ribas JG, Melo GC. Mielopatia associada ao vírus linfotrópico humano de células T do tipo 1 ( HTLV-1). Revista da Sociedade Brasileira de Medicina Tropical 35: 377-384, 2002.

87. Rocha FJ, Roedel G. Um caso de esquistossomose medular. Revista da Associação Médica de Minas Gerais 3: 23-26, 1952.

88. Rosenbaum RM, Ishii N, Tanowitz IH, Wittner M. Schsitosomiasis mansoni of the spinal cord. Report of a case. American Journal of Tropical Medicine and Hygiene 21: 182-184, 1972.

89. Salomão JF, Duarte F, Ancilom M, Paola F, Almeida Filho S. Esquistossomose medular, forma tumoral: relato de um caso. Arquivos de Neuropsiquiatria 45. 312-323, 1987.

90. Salum PNB, Machado LR, Spina-França A. Meningo-mielorradiculopatia na esquistossomose mansônica: Avaliação clínica e do líquido cefalorraqueano em 16 casos. Arquivos de Neuropsiquiatria 39: 289-295, 1981.

91. Sambon LW. Remarks on Schistosomum mansoni. Journal of Tropical Medicine and Hygiene 10: 303-304, 1907. Apud: Faust EC. An inquiry into the ectopic lesions in schistosomiasis. American Journal of Tropical Medicine 28: 175-199, 1948

92. Sanders KA, Khandji AG, Mohr JP. Gadolinium-MRI in acute transverse myelopathy. Neurology 40: 1614-1616, 1990.

93. Sanelli PC, Lev MH, Gonzalez RG, Schaefer PW. Unique linear and nodular MR enhancement pattern in schistosomiasis of the central nervous system: 
report of three patients. American Journal of Roentgenology 177: 14711474,2001

94. Santos EC, Campos GB, Diniz AC, Leal JC, Rocha MOC. Perfil clínico e critérios diagnósticos da mielorradiculopatia esquistossomótica. Arquivos de Neuropsiquiatria 59: 772-777, 2001.

95. Saxe N, Gordon W. Schistosomiasis of the spinal cord and skin. South African Medical Journal 49: 57-58, 1975.

96. Scaff M, Riva D, Spina-França A. Meningorradiculomielopatia esquistossomótica. Arquivos de Neuropsiquiatria 29: 227-233, 1971.

97. Scrimgeour EM. Non-traumatic paraplegia in northern Tanzania. British Medical Journal 283: 975-978, 1981.

98. Scrimgeour EM, Gajdusek DC. Involvement of the central nervous system in Schistosoma mansoni and S. haematobium infection: a review. Brain 108: 1023-1038, 1985.

99. Selwa LM, Brunberg JA, Mandell SH, Gerofalo EA. Spinal cord schistosomiasis: A pediatric case mimicking intrinsic cord neoplasm. Neurology 41: 755-757, 1991.

100. Sharif HS. Role of MR imaging in the management of spinal infections. American Journal of Roentgenology 158: 1333-1345, 1992.

101. Siddorn JA. Schistosomiasis and anterior spinal artery occlusion. American Journal of Tropical Medicine and Hygiene 27: 532-534, 1978.

102. Silbergleit R, Silbergleit R. Schistosomal granuloma of the spinal cord: Evaluation with MR imaging and intraoperative sonography. American Journal of Roenttenology 158: 1351-1353, 1992.

103. Silva LCS. Tratamento da mielorradiculopatia esquistossomótica com corticosteróides e avaliação pela ressonância magnética: um estudo prospectivo. Tese de mestrado, Universidade Federal de Minas Gerais, Belo Horizonte, MG, 2002.

104. Silva LCS, Kill CM, Lambertucci JR. Cervical spinal cord schistosomiasis. Revista da Sociedade Brasileira de Medicina Tropical 35: 543-544, 2002.
105. Spina-França A, Salum PNB, Limongi JCP, Berger A, Losso ER. Mielopatias: aspectos diagnósticos. Arquivos de Neuropsiquiatria 38: 360-366, 1980.

106. Suchet I, Klein C, Horwitz T, Lalla S, Doodha M. Spinal cord schistosomiasis: A case report and review of the literature. Paraplegia 25: 491-496, 1987.

107. Sztajnberg MC, Fernandes RCL. Mielite esquistossomótica: Relato de um caso tratado com praziquantel. Revista Brasileira de Neurologia 21: 61-66, 1985.

108. Truter PJ, Van der Merwe JV. Transverse myelitis caused by schistosomiasis during pregnancy. South African Medical Journal 71: 184-185, 1987.

109. Ueki K, Parisi JE, Onofrio BM. Schistosoma mansoni infection involving the spinal cord: Case report. Journal of Neurossurgery 82: 1065-1067, 1995.

110. Urban CA, Piovesan EJ, Almeida SM, Kowacs PA, Minguetti G, Werneck LC. Esquistossomose aguda com comprometimento cerebral: relato de caso. Arquivos de Neuropsiquiatria 54: 677-682, 1996.

111.Van Leusen H, Perquin WVM. Spinal cord schistosomiasis. Journal of Neurosurgery and Psychiatry 69: 690-691, 2000.

112. Wallace ID, Cosnett JE. Unexplained spastic paraplegia. South African Medical Journal 63: 689-691, 1983.

113. Watt G, Adpon B, Long GW, Fernando MT, Ranoa CP, Cross JH. Praziquantel in treatment of cerebral schistosomiasis. Lancet 2: 529-532, 1986.

114. Willemin-Clog MML, Pomme B, Callot J, Chapelo R, Montrieul B. Aspect clinique et therapeutique d'une radiculo-myelite a Schistosoma mansoni. Neurologie (Paris) 97: 521-525, 1957.

115. World Health Organization. The control of schistosomiasis. World Health Organization Technical Report Series 830: 1-86, 1993.

116. Yamagiwa K. Contribution to the etiology of Jacksonian epilepsy: Pathological changes of the cerebral cortex caused by distoma eggs. Journal of Kyoto Medical Association 3, 1889. Apud: Faust EC. An inquiry into the ectopic lesions in schistosomiasis. American Journal of Tropical Medicine 28: 175-199, 1948. 